\title{
Impact of Ethanol Dosing on the Long-Term Outcome of Alcohol Septal Ablation for Obstructive Hypertrophic Cardiomyopathy
} A Single-Center, Prospective, and Randomized Study

\author{
Josef Veselka, MD, PhD; Radka Duchoňová, MD; Jana Páleníčkova, MD; David Zemánek, MD; \\ Marie Tišerová, MD; Kateřina Linhartová, MD; Pavel Červinka, MD, PhD*
}

\begin{abstract}
Background The impact of ethanol dose on the long-term outcome of alcohol septal ablation (ASA) for obstructive hypertrophic cardiomyopathy was investigated.

Methods and Results Fifty-four patients (age 24-82 years; 65\% women) undergoing ASA were randomized into 2 groups according to the dose of injected ethanol: Group A 1-2 ml, Group B $>2 \mathrm{ml}$. Clinical and echocardiographic data were obtained at baseline and during follow-up. The volume of ethanol injected was $1.50 \pm 0.4$ and $2.60 \pm 0.6 \mathrm{ml}(\mathrm{p}<0.001)$ with a subsequent peak of creatine kinase-MB of $2.25 \pm 1.00$ and $2.62 \pm 1.57 \mu \mathrm{kat} / \mathrm{L}(\mathrm{p}=0.02)$ in Groups A and B, respectively. The median follow-up was 39 (range 6-72) months after ASA, during which 1 patient died and 1 repeat procedure was necessary in both groups of patients. Both groups had a significant and similar improvement in outflow pressure gradient, dyspnea (New York Heart Association functional class) and angina pectoris (Canadian Cardiovascular Society class) $(\mathrm{p}<0.001)$. There was a significant decrease in the left ventricular ejection fraction (LVEF) in Group B ( $81 \pm 7$ vs $75 \pm 7 \%$; $\mathrm{p}=0.002)$, but not in Group A ( $80 \pm 7$ vs 79 $\pm 7 \%$; $\mathrm{p}=0.67)$. Thinning of the basal septum was more pronounced in Group B than in Group A $(9.3 \pm 5.7$ vs $6.6 \pm 3.4 \mathrm{~mm}$; $\mathrm{p}=0.04)$.

Conclusions A lower dose of ethanol injected into the target septal branch reduces both the size of necrosis and subsequent thinning of the basal septum, and preserves LVEF during long-term follow-up. Moreover, the low dose (1-2 ml) is as safe and as hemodynamically efficacious as higher doses. (Circ J 2006; 70: 1550-1552)
\end{abstract}

Key Words: Alcohol ablation; Follow-up; Hypertrophic cardiomyopathy

$\mathbf{H}$ ypertrophic cardiomyopathy $(\mathrm{HCM})$ is a genetic cardiac disease with heterogeneous clinical and phenotypic expression. Obstruction of the left ventricular (LV) outflow tract caused by the hypertrophic basal septum and the systolic anterior motion of the mitral valve occurs in $20-30 \%$ of cases! Patients may remain asymptomatic their entire lives or present with symptoms at any age. Pharmacological therapy is the initial approach to relieve disabling symptoms and may include $\beta$-blockers, verapamil or disopyramide. Unfortunately, some patients treated conventionally are unresponsive to the medical therapy. These patients are considered good candidates for ventricular septal myectomy, alcohol septal ablation (ASA) or dual-chamber pacemaker implantation!-3

ASA has been developed as a potential alternative to surgical myectomy, which is still considered the "gold standard" in the non-pharmacological therapy of obstructive HCM 1,4 Current clinical studies have demonstrated both clinical and hemodynamic efficacy of ASA $5-10$ but there is an ongoing concern about the long-term impact of the resul-

(Received August 3, 2006; revised manuscript received September 19, 2006; accepted October 4, 2006)

Department of Cardiology, CardioVascular Center, University Hospital Motol, Prague, *Department of Cardiology, Hospital Usti $n$. Labem, Czech Republic

Mailing address: Josef Veselka, MD, Department of Cardiology, CardioVascular Center, University Hospital Motol, Prague 5, VÚvalu 84, 150 00, Czech Republic. E-mail: veselka.josef@seznam.cz tant myocardial scar, particularly if the injury is large 4 As was published previously, the lower dose of ethanol $(\leq 2 \mathrm{ml})$ seems to be sufficient to ensure marked hemodynamic improvement in the short-term follow up? In this prospective, single-center, and randomized study, we sought to determine the relationship between the ethanol dose used during ASA and a long-term clinical and hemodynamic outcome.

\section{Methods}

Study Population

The study population consisted of 54 consecutive patients ( 35 women and 19 men; mean age $56 \pm 14$ years) with drugrefractory symptoms caused by obstructive HCM. The definition of HCM is based on the presence of severe myocardial hypertrophy (wall thickness $\geq 15 \mathrm{~mm}$ ) in the absence of any overt local or systemic cause that could account for the degree of hypertrophy! All the patients satisfied the requirement of having the basal septal thickness (interventricular septum end-diastolic diameter (IVS)) greater than $15 \mathrm{~mm}$ and suffered from severe heart failure symptoms (New York Heart Association (NYHA) classes $\geq$ III) and/or angina pectoris (Canadian Cardiovascular Society (CCS) classes $\geq$ III) with a maximal $\mathrm{LV}$ outflow gradient greater than $50 \mathrm{mmHg}$ at rest or after provocative maneuvers according to the American College of Cardiology/European Society of Cardiology Clinical Expert Consensus Document on HCM!

All patients suffered from dyspnea and their mean func- 
Table 1 Baseline Clinical and Echocardiographic Characteristics of Patients Undergoing Alcohol Septal Ablation

\begin{tabular}{lccc}
\hline \hline & Group A & Group B & p value \\
\hline Age, years & $58 \pm 15$ & $53 \pm 14$ & 0.15 \\
Women, $n$ & 17 & 18 & 1 \\
IVS, $\mathrm{mm}$ & $21 \pm 4$ & $22 \pm 4$ & 0.44 \\
LVd, $\mathrm{mm}$ & $43 \pm 4$ & $44 \pm 4$ & 0.63 \\
PW, mm & $12 \pm 3$ & $12 \pm 3$ & 0.80 \\
LA, mm & $48 \pm 5$ & $47 \pm 4$ & 0.47 \\
LVEF, \% & $80 \pm 7$ & $81 \pm 7$ & 0.67 \\
LV outflow gradient, mmHg & $75 \pm 41$ & $71 \pm 41$ & 0.77 \\
Dyspnea, NYHA class & $2.8 \pm 0.6$ & $2.8 \pm 0.4$ & 0.80 \\
Angina pectoris, CCS class & $2.3 \pm 0.7$ & $2.3 \pm 0.7$ & 0.95 \\
Initially paced patients, $n$ & 2 & 6 & 0.25 \\
\hline
\end{tabular}

IVS, interventricular septum end-diastolic diameter; LVd, left ventricular end-diastolic diameter; $P W$, left ventricular posterior wall end-diastolic diameter; LA, left atrial end-systolic diameter; LVEF, left ventricular ejection fraction; LV, left ventricular; NYHA, New York Heart Association; CCS, Canadian Cardiovascular Society.

tional class (NYHA) was $2.8 \pm 0.7$. Fifty-one patients (94\%) suffered from angina pectoris and their mean functional class (CCS) was $2.3 \pm 0.9$. Thirteen patients (24\%) reported episodes of previous syncope.

The hospital institutional review board approved the present study. Following obtainment of informed consent, patients were randomized in a 1:1 fashion to receive either $\leq 2 \mathrm{ml}$ (low-dose, Group A) or $>2 \mathrm{ml}$ ethanol (standard dose, Group B) ethanol during ASA. There were no differences in the medical treatment between both groups. Baseline clinical and echocardiographic data are summarized in Table 1.

\section{ASA Technique}

Details of our ASA technique have been published previously?,8 In brief, the presence or absence of significant epicardial coronary artery disease was documented by coronary angiography. A temporary pacemaker was placed in all patients except those who already had a permanent pacemaker or defibrillator. A slightly oversized over-the-wire balloon catheter was introduced over a coronary wire and inflated in the putative septal perforator artery(ies). The optimal perforator was identified by echocardiographic opacification of the area of septal hypertrophy, without opacification of any other cardiac structure (myocardial contrast echocardiography-guided procedures)!1 ${ }^{1}$ We did not use more than 2 target arteries for ablation in a single patient.

The absence of a possible reflux of ethanol into the left anterior descending artery was confirmed by angiography. Ethanol was injected very slowly per fraction at a rate of $<1 \mathrm{ml} / \mathrm{min}$. The standard dose of ethanol was $1-1.5 \mathrm{ml}$ in Group A and 2.1-2.5 ml in Group B. Patients who did not reach the LV outflow gradient decrease $(\geq 50 \%)$ after the first ethanol injection received more ethanol $(1.6-2 \mathrm{ml}$ or $2.6-$ $4 \mathrm{ml}$ ). After the procedure, repeat hemodynamic and angiographic studies were performed. Patients were observed in the intensive care unit for at least $24 \mathrm{~h}$; the pacemaker lead was then removed if there was no episode of high-degree atrioventricular block. Creatine kinase (CK)-MB peak was determined at a 6-h interval during the postprocedural $24 \mathrm{~h}$.

\section{Clinical and Echocardiographic Assessment}

In all cases, clinical, morphologic, and hemodynamic data were assessed by an investigator who was blinded to the randomization status. Assessments were performed prior to the procedure and $\geq 6$ months after the ASA. The LV out-
Table 2 Clinical and Echocardiographic Characteristics at Follow-up After Alcohol Septal Ablation

\begin{tabular}{lccc}
\hline \hline & Group A & Group B & p value \\
\hline Follow-up duration, & $40 \pm 20$ & $39 \pm 19$ & \\
$\quad$ months (range) & $(6-72)$ & $(6-70)$ & 0.78 \\
IVS, mm & $15 \pm 4$ & $13 \pm 5$ & 0.11 \\
LVd, mm & $48 \pm 5$ & $48 \pm 5$ & 0.80 \\
PW, mm & $11 \pm 3$ & $12 \pm 3$ & 0.55 \\
LA, mm & $48 \pm 5$ & $47 \pm 5$ & 0.47 \\
LVEF, \% & $79 \pm 7$ & $75 \pm 7$ & 0.03 \\
LV outflow gradient, mmHg & $25 \pm 29$ & $21 \pm 21$ & 0.61 \\
Dyspnea, NYHA class & $1.4 \pm 0.9$ & $1.2 \pm 0.8$ & 0.25 \\
Angina pectoris, CCS class & $0.8 \pm 0.8$ & $0.6 \pm 0.5$ & 0.27 \\
Paced patients, $n$ & 6 & 7 & 1 \\
\hline
\end{tabular}

Abbreviations see in Table 1.

flow gradient was derived from the modified Bernoulli equation, pressure gradient $=4 \mathrm{~V}^{2}$, where $\mathrm{V}$ is the maximum velocity recorded in the LV outflow tract. Septal (IVS) and posterior wall thicknesses and LV end-diastolic diameter were measured from 2-dimensional images. At baseline, IVS thickness was measured in the basal segment of the septum (maximal septal thickness); at follow up, IVS thickness was measured in the thinnest part of the scar in the basal septum. The left atrium (LA) dimension was measured $\mathrm{b}$ using the M-mode in the parasternal long-axis view. LV ejection fraction (LVEF) was calculated with the use of Simpson's method and confirmed by the assessment of the investigator. All echocardiographic readings were blinded.

\section{Statistical Analysis}

Microsoft Excel with Analyse-It (Analyse-it Software Ltd, UK) was used for the study database and its analysis. Continuous variables are expressed as mean $\pm \mathrm{SD}$, where discrete variables are expressed as counts and percentages. Groups were compared by the means of Student's t-test (continuous variables) or Fisher's exact test (categorical variables). Pearson correlation coefficients and 95\% confidence interval (CI) were calculated to test correlation between ethanol volume injected (or CK-MB peak) and morphologic, hemodynamic or clinical changes. A p-value of $<0.05$ was considered statistically significant.

\section{Results}

Acute Results

All ASA procedures were uneventful except for 2 cases of sustained ventricular tachycardia during the procedure requiring immediate electrical cardioversion. Another 2 patients required electrical cardioversion for ventricular tachycardia at the coronary care unit during the $24 \mathrm{~h}$ following the ASA. Ventricular tachycardia occurrence was not dependent on the ethanol dose used during the procedure (2 cases in both groups).

Ethanol was injected into 1 septal branch except in 4 cases of very thin and numerous septal perforators in the proximal left anterior descending artery ( 2 cases in both groups). The volume of ethanol injected was $1.50 \pm 0.4$ and $2.60 \pm 0.6 \mathrm{ml}(\mathrm{p}<0.001)$ with a subsequent peak of CK-MB of $2.25 \pm 1.00$ and $2.62 \pm 1.57 \mu \mathrm{kat} / \mathrm{L}(\mathrm{p}=0.02)$ in Groups A and $\mathrm{B}$, respectively. The normal range of CK-MB is up to $0.42 \mu \mathrm{kat} / \mathrm{L}$. Ten patients (37\%) did not achieve a gradient decrease of $\geq 50 \%$ when the ethanol dose was below $1.5 \mathrm{ml}$ in Group A and 9 patients (33\%) did not achieve a gradient 
decrease of $50 \%$ when the ethanol dose was below $2.5 \mathrm{ml}$ in group B (NS). There was a significant correlation between peak CK-MB and the volume of ethanol injected $(\mathrm{r}=0.41,95 \% \mathrm{CI} 0.15$ to $0.61 ; \mathrm{p}=0.003)$. The other correlations between the ethanol dose or CK-MB peak and morphologic, clinical or hemodynamic changes after ASA were not significant.

\section{Follow-up}

The median duration of follow-up was 39 (range 6-72) months after ASA, during which 1 patient died (sudden death and bronchial carcinoma) and 1 repeat procedure was necessary in both groups of patients. Both groups had significant and similar improvement in outflow pressure gradient, dyspnea (NYHA functional class) and angina pectoris (CCS class) $(\mathrm{p}<0.001)$. However, there was a decrease in the LVEF in Group B $(81 \pm 7$ vs $75 \pm 7 \%$; $=0.002)$, but not in Group A ( $80 \pm 7$ vs $79 \pm 7 \%$; $=0.67) ; p=0.03$ for a difference between Group A vs B at follow up. Thinning of IVS was more pronounced in Group B than in Group A (9.3 \pm 5.7 vs $6.6 \pm 3.4 \mathrm{~mm}$; $\mathrm{p}=0.04)$. The LA diameter and $\mathrm{LV}$ posterior wall thickness did not change during follow-up.

Permanent pacemaker implantation was needed in 4 $(16 \%)$ of the initially non-paced patients in Group A and in $1(5 \%)$ of the initially non-paced patients in Group B $(\mathrm{p}=0.54)$. New bundle branch block occurred in $13(54 \%)$ patients in Group A and 15 (75\%) patients in Group B ( $\mathrm{p}=$ $0.20)$. There were no differences in the medical therapy of both groups $\beta$-blockers 19 vs 20 patients; $p=1$; calciumchannel blockers 7 vs 6 patients; $p=1$ ). Follow-up data are summarized in Table 2 .

\section{Discussion}

To the best of our knowledge, this is the first randomized study to demonstrate that a low dose of ethanol $(\leq 2 \mathrm{ml})$ is associated with the same long-term clinical, morphologic and hemodynamic outcome of ASA as higher doses used previously. Moreover, low doses of ethanol lead to the reduction of myocardial injury and result in the preservation of LV function in the long-term follow-up.

We believe the present study is important and has 3 clinical consequences. First, the lower dose of ethanol is associated with the preservation of LV systolic function. This finding is of crucial importance in the light of ongoing concern about the long-term impact of ASA. Second, as was found in previous short-term studies, there is a correlation between the amount of ethanol injected during a procedure and the extent of myocardial injury measured by a biomarker release?,9,12,13 However, the present study suggests that there is no relationship between the extent of myocardial injury and subsequent hemodynamic or clinical improvement at long-term follow-up. Also, the clinical effectiveness of ASA is not dependent upon the volume of ethanol used (if the range of ethanol dose is $1-4 \mathrm{ml}$ ), but is most likely dependent on the precise determination of the appropriate septal territory. Finally, some centers that perform a large number of ASA procedures are using lower doses of ethanol than previously used, which is associated with smaller extent of septal necrosis! However, this clinical practice has been based only on individual experience of catheterization staff up to now. The present study supports the low-dose ethanol policy. In contrast, it still remains questionable as to whether ultra-low ethanol dosing $(<1 \mathrm{ml})$ with sub-selective injections into secondary septal branches would be similarly effective.

\section{Study Limitations}

First, because of the great variation in the septal perforator branches ${ }^{14}$ their vascular territory and septal anatomy, it is impossible to recommend only 1 alternative to the ethanol dose strategy used during ASA. Second, the principal finding of the present study is that the low-dose ethanol used resulted in less CK-MB elevation and no fall in LVEF compared to higher doses where LVEF did fall significantly, albeit well within the normal range (from 81 to $75 \%$ ). However, it is still not clear whether the small differences in LVEF will be of any long-term clinical relevance. Finally, the total number of patients in the present study is limited.

Notwithstanding the limitations, the present study shows that the lower dose of ethanol injected into the target septal branch reduces both the size of necrosis and subsequent thinning of the basal septum, and preserves LVEF during long-term follow-up. Moreover, the low dose (1-2 ml) is as safe and hemodynamically efficacious as higher doses.

\section{References}

1. Maron BJ, McKenna WJ, Danielson GK, Kappenberger LJ, Kuhn HJ, Seidman CE, et al. American College of Cardiology/European Society of Cardiology Clinical Expert Consensus Document on Hypertrophic cardiomyopathy. Eur Heart J 2003; 24: 1965-1991.

2. Hozumi T, Ito T, Suwa M, Sakai Y, Kitaura Y. Effects of dual-chamber pacing on regional deformation in patients hypertrophic obstructive cardiomyopathy. Circ J 2006; 70: 63-68.

3. Honda T, Shono H, Koyama J, Tsuchiya T, Hayashi M, Hirayama T, et al. Impact of right atrial-left ventricular dual-chamber permanent pacing in patients with severely symptomatic hypertrophic obstructive cardiomyopathy. Circ J 2005; 69: 536-542.

4. Maron BJ. Surgery for hypertrophic obstructive cardiomyopathy: Alive and quite well. Circulation 2005; 111: 2016-2018.

5. Faber L, Seggewiss H, Welge D, Fassbender D, Schmidt HK, Gleichmann U, et al. Echo-guided percutaneous septal ablation for symptomatic hypertrophic obstructive cardiomyopathy: 7 years of experience. Eur J Echocardiogr 2004; 5: 347-355.

6. Chang SM, Lakkis NM, Franklin J, Spencer WH, Nagueh SF. Predictors of outcome after alcohol septal ablation therapy in patients with hypertrophic obstructive cardiomyopathy. Circulation 2004; 109: 824-827.

7. Veselka J, Duchoňová R, Procházková Š, Páleníčková J, Sorajja P, Tesař D. Effects of varying ethanol dosing in percutaneous septal ablation for obstructive hypertrophic cardiomyopathy on early hemodynamic changes. Am J Cardiol 2005; 95: 675-678.

8. Veselka J, Duchoňová R, Páleníčková J, Zemánek D, Šváb P, Hájek $\mathrm{P}$, et al. Age-related hemodynamic and morphologic differences in patients undergoing alcohol septal ablation for hypertrophic obstructive cardiomyopathy. Circ J 2006; 88: 27-32.

9. Boekstegers P, Steibigler P, Molnar A, Schwaiblmair M, Becker, Knez A, et al. Pressure-guided nonsurgical myocardial reduction induced by small septal infarctions in hypertrophic obstructive cardiomyopathy. J Am Coll Cardiol 2001; 38: 846-853.

10. Kuhn H, Seggewiss H, Gietzen FH, Boekstegers P, Neuhaus L, Seipel L. Catheter-based therapy for hypertrophic obstructive cardiomyopathy. First in-hospital outcome analysis of the German TASH Registry. Z Kardiol 2004; 93: 23-31.

11. Abbas AE, Brewington SD, Dixon SR, Grines CL, O'Neill W. Alcohol septal ablation for hypertrophic obstructive cardiomyopathy. $J$ Interven Cardiol 2005; 18: $155-162$.

12. van Dockum WG, ten Cate FJ, ten Berg JM, Beek AG, Twisk JW, Vos J, et al. Myocardial infarction after percutaneous transluminal septal myocardial ablation in hypertrophic obstructive cardiomyopathy: Evaluation by contrast-enhanced magnetic resonance imaging. J Am Coll Cardiol 2004; 43: 27-34.

13. Li ZQ, Cheng TO, Liu L, Jin YZ, Zhang M, Guan RM. Experimental study of relationship between intracoronary alcohol injection and the size of resultant myocardial infarct. Int J Cardiol 2003; 91: 93-96.

14. Singh M, Edwards WD, Holmes DR, Tajik J, Nishimura RA. Anatomy of the first septal perforating artery: A study with implications for ablation therapy for hypertrophic cardiomyopathy. Mayo Clin Proc 2001; 76: 799-802. 